УДК 316.6

\title{
B.в. Васина
}

\section{ФЕНОМЕН ФАСИЛИТАЦИИ СОЦИАЛЬНОГО ВЗАИМОДЕЙСТВИЯ: ЭФФЕКТ, МЕХАНИЗМЫ, ЗАКОНОМЕРНОСТИ}

В эпоху экспоненциального развития цивилизации уплотняется социальное взаимодействие с расширением диапазона представлений и норм жизни, и, соответственно, в обществе возрастает вероятность конфликтности. Исследование проблемы социального взаимодействия представлено недостаточно и остается актуальным в научном мире. Автором (совместно с Р.Г. Халитовым и И.М. Юсуповым) разработана концепция психосоциального диссонанса (понятие и модель), которая стала фундаментом для исследования социального взаимодействия, а вероятностная модель психосоциального диссонанса - основой для математического (формульного) определения и моделирования социального взаимодействия. Постнеклассическая наука, в рамках которой автор проводит исследования, изучая сложные саморазвивающиеся системы, природные комплексы, включающие человека, с расширением рамок понятий научной методологии и научного подхода к нему. Для понимания фасилитации социального взаимодействия в присутствии наблюдателя используется «антропный принцип», устанавливающий связь существования человека (как наблюдателя) с физическими параметрами мира. На основе теоретических исследований введено понятие фасилитации и показан эффект ее социального взаимодействия. Предложено описание механизма фасилитации социального взаимодействия на основе модели психосоциального диссонанса и уровневой модели психосоциальных явлений. Проведены эмпирические исследования и показаны закономерности фасилитации социального взаимодействия; предложена методика определения (численного) влияния фасилитатора на социальное взаимодействие. Модель фасилитации социального взаимодействия может стать основой для дальнейших психологических исследований и открывает возможность применения полученных результатов для использования в психологических практиках, а также в подготовке грамотных профессиональных фасилитаторов.

Ключевые слова: механизмы и закономерности фасилитации, модель социального взаимодействия, фасилитации социального взаимодействия, психосоциальный диссонанс, системно-онтологический подход.

DOI: $10.35634 / 2412-9550-2019-29-3-268-275$

\section{Введение}

В век глобализации в разных сферах жизни общества насыщается интенсивность социального взаимодействия. Как следствие - раздвигается спектр представлений субъектов взаимодействия о жизни в разных культурах и стратах общества. В силу устоявшихся паттернов (норм) поведения и степени готовности к изменениям возникает психосоциальный диссонанс [24], стимулирующий субъектную психическую напряженность между ними и предконфликтную ситуацию, развитие которой возможно по двум сценариям: 1) конфликт с разрушительными последствиями; 2) сотрудничество как предпосылка к развитию отношений между субъектами взаимодействия. При этом субъекты взаимодействия сознательно или бессознательно выбор делают самостоятельно.

На выбор гипотетично влияют: объективно сложившаяся ситуация взаимодействия; личностные и психические особенности субъектов взаимодействия, социальный фон, социальная среда. Среди последних неоднозначную роль играет эффект фасилитации, впервые зафиксированный в конце XIX в. [3]. При высокой цене ожидаемого результата влияние этого феномена может приводить к отягощенным последствиям в межгрупповых и межгосударственных отношениях. Сам термин «фасилитация» имеет латинский корень: «упрощать, ускорять, способствовать, стимулировать». Неоднозначность понимания терминов «фасилитатор» и «фасилитация» вызывает необходимость упорядочивания родовидовых отношений этих понятий в социальном взаимодействии: родовое понятие - это посторонний, присутствующий при социальном взаимодействии. Видовые понятия: пассивный - наблюдатель; активныц - фасилитатор. Далее приведем видовые понятия для понятия фасилитатор: континуум между полюсами: 1) фасилитатор - наблюдатель и 2) фасилитатор - участник социального взаимодействия. Именно в последнем значении трактуется фасилитация в современных исследованиях, хотя открытие самого эффекта понималось в первом значении (посторонний). 


\section{Современное состояние исследований}

Р.С. Димухаметова рассматривала феномен фасилитации при повышении квалификации педагогов [7]. Е.Г. Врублевская [6], Л.И. Тимонина [21], В.Е. Сумина [20], М.Н. Смирнова [19], О.В. Пушкина [18] изучали педагогические условия развития у педагога способности к фасилитирующему общению в процессе его профессиональной деятельности, социально-педагогическую фасилитацию учебной деятельности неуспевающих школьников-подростков, педагогическое взаимодействие как фактор фасилитации психофизической нагрузки на детей с ограниченными возможностями здоровья, образовательную среду школы как условие фасилитации профессионального самоопределения учащихся. Развитие фасилитации педагогов изучали И.В. Жижина [10], фасилитацию личностной адаптированности в период поздней взрослости средствами творческого самовыражения - А.А. Филозоп [22], фасилитацию личностного роста младших подростков в процессе логопсихотерапии - А.Ю. Кругликова [12]. Понятие фасилитации используется также при преодолении трудностей в изучении иностранных языков $[1 ; 11]$ и в посредническом урегулировании конфликтов [12].

Теоретически не обоснованы пока психологические закономерности, принципы и механизмы оптимизации социального взаимодействия субъектов при нейтрализации различных межличностных и межгрупповых конфликтов.

Психологическая проблема: каковы закономерности и механизмы феномена фасилитации социального взаимодействия.

Цель исследования - обосновать психологическую природу феномена фасилитации в социальном взаимодействии.

\section{Методы исследования}

Для описания феномена фасилитации социального взаимодействия использованы системный (Б.Ф. Ломов, В.Г. Буданов, Г.Г. Малинецкий, С.П. Курдюмов, и др.), онтологический (С.Л. Рубинштейн, Н.И. Леонов, В.В. Панов, Ш.Р. Хисамбеев), вероятностный и герменевтический (В.В. Налимов) подходы, применяемые в постнеклассическом развитии современной науки [5]. Д.А. Леонтьев провел анализ (обзор) состояния неклассической психологии по таким характеристикам, как способы построения психологического знания и психологической практики, отличающиеся от классического подхода [13]. Под классической психологией он понимает парадигму, строящуюся по образцу естественных наук, где существует субъект-объектное познание, основанное на методологии эмпирического исследования [8; 9]. К неклассическим будут относиться подходы, пытающиеся противопоставить естественнонаучной методологии гуманитарную. В обнаружении феномена фасилитации социального взаимодействия гуманитарный подход имеет две ключевые особенности. Первая - активное включение в рассмотрение социально-исторического, культурного контекста, рассмотрение человека не как вещи среди вещей, а как укорененного в мире культуры, с которым он взаимодействует и из которого себя строит. Т. е. гуманитарная, или неклассическая, психология рассматривает личность не как природный объект, а как культурный, искусственный объект, как произведение [15]. Вторая особенность - рассмотрение личности как творца этого произведения, т. е. активного субъекта, не столько формируемого извне или изнутри заранее заложенными программами, сколько - самосозидающего, самодетерминируемого. Только гуманитарный подход в состоянии понять субъектность человека (agency) - его способность быть не просто побуждаемым изнутри и извне, но источником и причиной своих действий.

Эффект фасилитации можно измерить тремя способами: (видео)наблюдением, психофизиологической фиксацией результатов эксперимента и тестированием.

\section{Результаты исследования}

Наша концепция фасилитации социального взаимодействия с точки зрения системного подхода основывается на следующих положениях, согласующихся с принципами системного подхода Б.Ф. Ломова [14]:

- система находится в единстве через взаимодействие элементов, а социальные системы составляют целое через социальное взаимодействие субъектов социального взаимодействия (личности, группы, общества); т. е. ее самоорганизация происходит через взаимодействие; 
- существует иерархия систем: большие системы включают меньшие: от «квантов» до «единого», или малые системы образуют большие системы - объекты взаимодействия с новыми эмерджентными свойствами;

- устойчивость, единство системы сохраняются через рефлексию системы в целом, через метапозицию наблюдателя (фасилитатора);

- познаваемость, оценка и саморазвитие системы в целом возможны только через наблюдателя, находящегося вне системы (теорема Геделя).

Таким образом, необходимы три составляющих для образования, развития и сохранения социальных систем: 1 - элементы системы (субъекты социального взаимодействия - личность, малая и большая социальные группы, общество, сообщество), 2 - взаимодействие элементов и 3 - наблюдатель, которые находятся в единстве. Так возникает система, для жизнеспособности которой необходим наблюдатель с метапозиции для ее самоидентификации системы.

Всё происходит в поле социального взаимодействия, и функция наблюдателя (фасилитатора) есть отражение (рефлексия) поля социального взаимодействия, напряженность которого ведет к социальным изменениям, т. е. происходит фасилитация/ингибиция (изменение - «улучшение/ухудшение») социального взаимодействия. Фасилитация социального взаимодействия представляет собой процесс влияния на социальное взаимодействие в социуме в присутствии фасилитатора (наблюдателя). Оценка влияния («хорошо или плохо») относительна и зависит от точки зрения «оценщика»: к какой социальной группе он принадлежит, к каким нормам, правилам ссылается при сравнении.

\section{Эффект фасилитации социального взаимодействия}

В современных практических технологиях этот термин интерпретируется как эффект улучшения групповой динамики под недирективным управлением так называемого «фасилитатора».

Эффект фасилитации социального взаимодействия - это изменение, повышение продуктивности социального взаимодействия партнеров по коммуникации в процессе фасилитации при актуализации в их сознании образов социального взаимодействия: субъектов и коммуникативной ситуации в континууме фасилитация $\div$ ингибиция в присутствии наблюдателя. При этом сам наблюдатель (фасилитатор) может стать участником социального взаимодействия.

При исследовании фасилитации социального взаимодействия мы использовали онтологический подход, рассматривающий существование психики как формы бытия и как предмета исследования [26]. Наше понимание онтологического подхода основано на модели разных уровней бытия: физической реальности и психической реальности [25]. Соответственно, фасилитатор может существовать в физическом и психическом планах и фасилитация может протекать в этих же планах.

Присутствие фасилитатора позволяет субъекту взглянуть на систему социального взаимодействия со стороны Я-рефлексирующего и Я-наблюдателя, получив возможность принять взвешенное решение в точке выбора возникшего психосоциального диссонанса (ПСД). Эти положения согласуются с концепцией диалогической структуры «Я» Губерта Херманса [27]. В социальном взаимодействии с фасилитатором в множестве «Я» активизированы наблюдатель (Я в континууме наблюдатель $\div$ участник взаимодействия. Функциями фасилитатора социального взаимодействия могут обладать учителя, администраторы, коллеги, соученики и др.

\section{Механизмы фасилитации социального взаимодействия}

Согласно предложенной нами модели [4; 25], социальное взаимодействие начинается с мира вещественного, материального (первый уровень) при встрече субъектов социального взаимодействия (CB). Это взаимодействие изменяет физическое состояние через перцепцию на втором уровне. На третьем уровне формируются образ, и понятие, обозначаемое словом.

Механизм фасилитации социального взаимодействия в сознании представляется как:

- социальная категоризация;

- идентификация (личностная или социальная);

- адаптация;

- социальное сравнение (оценка);

- рефлексия и возникновение психосоциального диссонанса (ПСД);

- выбор пути развития: либо новообразование; либо психологическая защита и психическая напряженность. В точке ПСД происходит выбор взвешенного, оптимального решения [23]. 
В точке ПСД как в точке неустойчивости, неопределенности системы взаимодействия субъектов (групп) - присутствие фасилитатора оказывается значимым, что особенно заметно в рефлексии субъектов взаимодействия, когда они могут изменять свой статус из Я-взаимодействующего в Ярефлексирующего (внутреннего наблюдателя) для принятия решения. С принятием решения (сознательно или бессознательно) они могут вернуться в статус Я-взаимодействующего.

\section{Вероятностная модель фасилитации социального взаимодействия}

Математическую метафору можно представить в виде распределения плотности вероятности представлений присущих субъектам взаимодействия (CB): описать функционально при помощи формул ПСД, как характеристик социального взаимодействия [23; 24]. При нормальном распределении Гаусса значения нормы представлений находятся в интервале от $\left(X_{c p}-\sigma\right)$ до $\left(X_{c p}+\sigma\right)$, т. е. этот интервал зона комфорта для субъекта взаимодействия. В случае двух и более измерений этот интервал становится кругом.

Во время фасилитации социального взаимодействия «реагирование» происходит на 3 уровне (психическом) на сигнал, поступивший с 1 уровня (физического). Граничные точки ПСД $\left(X_{c p}-\sigma\right)$ и $\left(X_{c p}+\sigma\right)$ - это точки бифуркации, выбора, принятия решения. СВ стремится к представлениям с большей вероятностью, к более привычным - к центру зоны комфорта (круга), к $X_{c p}$, т.е. к значениям с максимальной вероятностью.

Фасилитатор выводит из состояния покоя и приводит в возбуждение (движение) представления (мысли) СВ, а также меняет социальное взаимодействие. Наибольшее влияние фасилитатор оказывает на социальное взаимодействие, когда СВ находятся в точках психосоциального диссонанса $\left(X_{c p}-\right.$ $\sigma)$ и $\left(X_{c p}+\sigma\right)$, т. е. точках неустойчивости, неопределенности, или - точках выбора: 1) обратно в центр круга, где всё устойчиво, система закрыта (нет обмена с внешним миром); или 2) выход за круг - развитие, творчество - система открыта (предпосылка для развития - обмен энергией и информацией с внешним миром).

В точках ПСД наблюдается максимальная скорость изменения плотности вероятности (вторая производная равна нулю), т. е. неустойчивость максимальная. В точке $X_{\mathrm{cp}}$ скорость изменений, первая производная плотности вероятности равна нулю, т. е. устойчивость максимальная.

Присутствие фасилитатора позволяет субъектам социального взаимодействия взглянуть на систему со стороны (Я-рефлексирующий, Я-наблюдатель) и получить возможность изменить социальное взаимодействие, приняв решение в точке выбора. По сути мы говорим о «внутреннем», виртуальном Я-фасилитаторе. Контроль, управление, решение, изменение происходят в психическом, смысловом и семантическом пространстве на основе множества «Я». Внешние стимулы-сигналы (внешний фасилитатор) и обратная реакция-поведение происходят в физическом пространстве.

\section{Закономерности фасилитации социального взаимодействия}

Автором статьи была разработана методика выявления роли фасилитатора в социальном взаимодействии и проведена диагностика склонности к восприятию фасилитационного воздействия в конфликтных ситуациях по стратегиям поведения Томаса (в модификации В.В. Васиной) [4]. Выборка состояла из 300 студентов дневного и заочного отделений КИУ обоих полов в возрасте от 17 до 55 лет.

Закономерности проверялись через корреляционные связи. В психическом пространстве фасилитация - это сближение представлений, т. е. сценариев субъектов социального взаимодействия. $B$ физическом пространстве - изменение поведения в конфликтной ситуации, в лучшем случае, на сотрудничество, компромисс.

$B$ психическом пространстве ингибиция - это расхождение представлений, сценариев социального взаимодействия. $B$ физическом пространстве - изменение поведения в конфликтной ситуации, в худшем случае, - на противоборство, избегание.

Мерой социального взаимодействия является ПСД и количественно - коэффициент ПСД $-K_{D}$. Следовательно мерой фасилитации соииального взаимодействия будет изменение ПСД $\left(K_{D}\right)$ в присутствии фасилитатора $(\Phi): \Delta \Phi=\Delta K_{D}=K_{D}(c \Phi)-K_{D}(б е з ~ \Phi)$, т. е. насколько напряжение социального взаимодействия изменилось в процессе фасилитации. Если $\Delta K_{D}>0$, т. е. диссонанс (психическое напряжение) увеличился, то это - показатель ингибиции; если $\Delta K_{D}<0$, т. е. диссонанс между субъектами социального взаимодействия уменьшился, т. е. произошло сближение представлений, то это показатель фасилитации социального взаимодействия. Внутренний или внешний фасилитатор запускает механизм изменения состояний статуса взаимодействующего. 
Фасилитатор сохраняет, стабилизирует (улучшает) групповые нормы социального взаимодействия, стратегии поведения. Чем больше значение данной стратегии поведения, т. е. чем больше вероятность такой стратегии поведения в социальном взаимодействии, тем устойчивее эта стратегия поведения, тем меньше отклонение ее значений (исходной вероятности) в процессе фасилитации. Покажем это через наши эмпирические исследования.

В таблице представлены эмпирически полученные корреляции, где $\Delta$ - разница значений стратегии поведения (СП) в присутствии фасилитатора и без фасилитатора, т. е. $\Delta=C \Pi(c \Phi)-C \Pi(б е з ~ \Phi)$. Проанализируем, например, корреляцию: $(\Delta$ сотруд $\div$ сотруд $)=-0,55$. Чем большее значение имеет характеристика сотрудничества $(x)$, тем меньше влияние фасилитатора на изменение характеристики $(\Delta x)$, т. к. $\Delta x \sim \kappa^{*} x$.

\section{Корреляционные зависимости влияния фасилитатора на стратегии поведения}

\begin{tabular}{|l|c|c|c|c|c|}
\hline$\Delta x$ & Противоборство & Сотрудничество & Компромисс & Избегание & Уступка \\
\hline Противоборство & $\mathbf{- 0 , 3 6}$ & 0,10 & 0,15 & 0,13 & 0,08 \\
\hline Сотрудничество & 0,08 & $\mathbf{- 0 , 5 5}$ & 0,00 & 0,17 & $\mathbf{0 , 2 5}$ \\
\hline Компромисс & 0,14 & 0,08 & $\mathbf{- 0 , 4 8}$ & $-0,06$ & $\mathbf{0 , 2 8}$ \\
\hline Избегание & 0,01 & $\mathbf{0 , 2 6}$ & 0,14 & $\mathbf{- 0 , 3 8}$ & $-0,04$ \\
\hline Уступка & $\mathbf{0 , 2 0}$ & 0,16 & 0,12 & 0,07 & $\mathbf{- 0 , 5 5}$ \\
\hline $\begin{array}{l}\text { Идентификация- } \\
\text { персональная }\end{array}$ & $\mathbf{- 0 , 3 0}$ & $\mathbf{0 , 3 3}$ & 0,08 & $\mathbf{- 0 , 2 0}$ & 0,16 \\
\hline $\begin{array}{l}\text { Идентификация- } \\
\text { социальная }\end{array}$ & $\mathbf{0 , 3 0}$ & $\mathbf{- 0 , 3 3}$ & $-0,08$ & $\mathbf{0 , 2 0}$ & $-0,16$ \\
\hline Пассивность & $\mathbf{0 , 2 1}$ & $\mathbf{0 , 3 4}$ & 0,03 & $\mathbf{- 0 , 2 4}$ & $\mathbf{- 0 , 3 8}$ \\
\hline Активность & $\mathbf{- 0 , 2 1}$ & $\mathbf{- 0 , 3 4}$ & $-0,03$ & $\mathbf{0 , 2 4}$ & $\mathbf{0 , 3 8}$ \\
\hline
\end{tabular}

\begin{tabular}{|l|c|c|c|c|}
\hline$\Delta x$ & $\begin{array}{l}\text { Идентификация- } \\
\text { персональная }\end{array}$ & $\begin{array}{l}\text { Идентификация- } \\
\text { социальная }\end{array}$ & Пассивность & Активность \\
\hline Противоборство & $\mathbf{- 0 , 2 4}$ & $\mathbf{0 , 2 4}$ & $\mathbf{0 , 2 1}$ & $\mathbf{- 0 , 2 1}$ \\
\hline Сотрудничество & $\mathbf{0 , 2 4}$ & $\mathbf{- 0 , 2 4}$ & $\mathbf{0 , 3 2}$ & $\mathbf{- 0 , 3 2}$ \\
\hline Компромисс & $-0,12$ & 0,12 & $-0,01$ & 0,01 \\
\hline Избегание & $\mathbf{- 0 , 2 6}$ & $\mathbf{0 , 2 6}$ & $\mathbf{- 0 , 2 5}$ & $\mathbf{0 , 2 5}$ \\
\hline Уступка & $\mathbf{0 , 3 5}$ & $\mathbf{- 0 , 3 5}$ & $\mathbf{- 0 , 3 4}$ & $\mathbf{0 , 3 4}$ \\
\hline Идентификация-персональная & $\mathbf{- 0 , 4 8}$ & $\mathbf{0 , 4 8}$ & 0,01 & $-0,01$ \\
\hline Идентификация-социальная & $\mathbf{0 , 4 8}$ & $\mathbf{- 0 , 4 8}$ & $-0,01$ & 0,01 \\
\hline Пассивность & 0,06 & $-0,06$ & $\mathbf{- 0 , 4 5}$ & $\mathbf{0 , 4 5}$ \\
\hline Активность & $-0,06$ & 0,06 & $\mathbf{0 , 4 5}$ & $\mathbf{- 0 , 4 5}$ \\
\hline
\end{tabular}

Аналогично для других стратегий поведения, полученных в эмпирическом исследовании, все диагональные коэффициенты корреляции по всем стратегиям поведения отрицательные и достаточно высокие. Это говорит о том, что фасилитатор сохраняет групповые нормы выборки по этим характеристикам.

Таким образом, отрицательная корреляционная связь между $x$ и его изменением $\Delta x$ по одной характеристике $(x)$ говорит об устойчивости этой характеристики к изменениям в процессе фасилитации, влиянию фасилитатора. Чем более выражены характеристики социального взаимодействия (стратегии поведения), тем меньше воздействие фасилитатора по этой характеристике (диагональные элементы в корреляционной матрице).

Фасилитатор, внутренний или внешний, запускает механизм изменения состояний взаимодействия. С точки зрения вероятностной, нечеткой логики Бейеса-Налимова, когда появляется фасилитатор (ситуация $\boldsymbol{y}$ ) и наблюдает социальное взаимодействие $\boldsymbol{\mu}$ (как бы читает «текст социального взаимодействия»), то изменяется социальное взаимодействие («текст») - его эволюция связана со спонтанным появлением «фильтра-окна»: $\boldsymbol{p}(\boldsymbol{y} / \boldsymbol{\mu})$ - плотность вероятности воздействия фасилитатора $(\boldsymbol{y})$ на социальное взаимодействие $(\boldsymbol{\mu})$, которое мультипликативно взаимодействует с исходной функцией $\boldsymbol{p}(\boldsymbol{\mu})$ - плотность вероятности исходного взаимодействия. Результат воздействия фасилитатора задается известной формулой Бейеса: 


$$
p(\mu / y)=k p(\mu) p(y / \mu)
$$

где плотность вероятности $\boldsymbol{p}(\boldsymbol{\mu} \boldsymbol{y})$ определяет семантику (смысл) нового текста после эволюционного толчка $\boldsymbol{y}$ - вероятность социального взаимодействия после появления фасилитатора; $\boldsymbol{k}$ - константа нормировки.

Формула Бейеса в этом случае выступает как силлогизм: из двух посылок $\boldsymbol{p}(\boldsymbol{\mu})$ и $\boldsymbol{p}(\boldsymbol{y} / \boldsymbol{\mu})$ с необходимостью следует текст с новой семантикой $\boldsymbol{p}(\boldsymbol{\mu} / \boldsymbol{y})$. В силлогизме Бейеса, в отличие от категорического силлогизма Аристотеля, как обе посылки, так и возникающие из них следствия носят не атомарный, а вероятностно размытый характер, и хотя бы вторая из посылок носит условный (обусловленный ситуацией $\boldsymbol{y}$ ), а не категорический характер $[25 ; 26]$. Формула для процесса фасилитации социального взаимодействия читается следующим образом: плотность вероятности социального взаимодействия $(\boldsymbol{\mu})$ в присутствии фасилитатора $(\boldsymbol{y})$ равна плотности вероятности социального взаимодействия до фасилитатора, умноженной на плотность вероятности влияния фасилитатора (y) на социальное взаимодействие $(\boldsymbol{\mu})$.

Сравнение формулы корреляции $\Delta x \sim \kappa^{*} x$ с формулой Бейеса-Налимова показывает их сходство формул. Тогда плотность вероятности влияния фасилитатора пропорциональна $(\sim)$ коэффициенту корреляции, т. е. коэффициент корреляции может выступить показателем плотности вероятности влияния фасилитатора по этой характеристике. Это методологическая новизна численного определения влияния фасилитатора.

\section{Выводы}

На основе теоретических исследований выявлен эффект и представлены механизмы фасилитации социального взаимодействия. На основе эмпирических исследований показаны закономерности и определена методика выявления (численного) влияния фасилитатора на социальное взаимодействие.

Отметим, что работы по фасилитации носят в основном практический, прикладной характер, как правило, в области организационного поведения. Следует также отметить недостаточную разработанность в отечественной психологии проблематики фасилитации в целом, что обусловлено, на наш взгляд, узкой трактовкой ее содержательной сущности. Кроме того, феномен фасилитации не изучался с точки зрения междисциплинарного подхода. Мы предполагаем, что интеграция существующих научных подходов к изучению феномена фасилитации социального взаимодействия позволит сформировать единую концепцию фасилитации в рамках социальной психологии, что поможет в дальнейшей разработке интегративного социально-психологического подхода: в обосновании возможности и целесообразности выделения психологии фасилитации социального взаимодействия как самостоятельного научного направления, имеющего собственный предмет изучения и собственную область исследования; специфические понятия; методологические основы и методические средства.

\section{СПИСОК ЛИТЕРАТУРЫ}

1. Акоста В.Е. Психолого-педагогическая процедура фасилитации положительного переноса в овладении двумя иностранными языками: автореф. дис. ... канд. психол.наук: 19.00.07, 13.00.02 / Тамбовский гос. ун-т им. Г.Р. Державина. Тамбов, 2012. 26 с.

2. Алексеев А.В. Посреднические технологии регулирования социальных конфликтов: дис. ... канд. социол. наук: 22.00.08. Орел, 2005. 192 с.

3. Большая психологическая энциклопедия. URL: http://psychology.academic.ru/7371

4. Васина В.В. Эффект фасилитации социального взаимодействия // Процедуры и методы экспериментальнопсихологических исследований. М.: ИПРАН, 2016. С. 767-774.

5. Васина В.В. Эффект фасилитации социального взаимодействия в аспекте конфликта // Социальный мир человека. Вып. 6: Материалы VI Междунар. науч.-практ. конф. «Человек и мир: миросозидание, конфликт и медиация в интеркультурном мире», 14-16 апреля 2016 г. Ижевск: ERGO, 2016. C. 22-27.

6. Врублевская Е.Г. Педагогические условия развития у педагога способности к фасилитирующему общению в процессе его профессиональной деятельности (На материале учреждений дополнительного образования детей): дис. ... канд. пед. наук: 13.00.01: Хабаровск, 1999. 226 с.

7. Димухаметов Р.С. Фасилитация в системе повышения квалификации педагогов: дис. ... докт. пед. наук: 13.00.08: Магнитогорск, 2006.398 с.

8. Дорфман Л.Я. Методологические основы эмпирической психологии. М.: Смысл; ИЦ «Академия», 2005.

9. Дорфман Л.Я. Эмпирическая психология: исторические и философские предпосылки. М.: Смысл, 2003. 
10. Жижина И.В. Психологические особенности развития фасилитации педагога: дис. ... канд. психол. наук: 19.00.07: Екатеринбург, 2000. 153 с.

11. Комарова Е.Ю. Психолого-педагогическая фасилитация преодоления трудности и сложности языковых тестов: автореф. дис. ... канд. психол. наук: 19.00.07, 13.00.02 / Тамбовский гос. ун-т им. Г.Р. Державина. Тамбов, 2012. $23 \mathrm{c}$.

12. Кругликова А.Ю. Психологические особенности личностного роста младших подростков в условиях разновозрастного коллектива: На примере групп семейной логопсихотерапии: дис. ... канд. психол. наук: 19.00.13. Ростов-н/Д, 2006. 224 с.

13. Леонтьев Д.А. Неклассический вектор в современной психологии // Постнеклассическая психология. Социальный конструкционизм и нарративный подход. № 1 (2). 2005. C. 51-72. URL: http://narrativepsy.narod.ru/ num1-2005.html.

14. Ломов Б.Ф. Системность в психологии. 1996. URL: https://ru.wikipedia.org/wiki/\%D07.

15. Мамардашвили М.К. Философия и личность // Человек. 1994. № 5. С. 5-19.

16. Налимов В.В. Вероятностная модель языка. М.: Наука, 1974. 272с.

17. Налимов В.В. Спонтанность сознания: Вероятностная теория смыслов и смысловая архитектоника личности. М.: Изд-во «Прометей» МГПИ им. Ленина, 1989. 190с.

18. Пушкина О.В. Образовательная среда школы как основополагающее условие фасилитации профессионального самоопределения учащихся: автореф. дис. ... канд. пед. наук: 13.00 .01 / ФГБОУ ВПО «Томский гос. педагогический университет». Томск, 2012. 23 с.

19. Смирнова М.Н. Педагогическое взаимодействие как фактор фасилитации психофизической нагрузки на детей с ограниченными возможностями здоровья в реабилитационном центре: дис. ... канд. пед. наук: 13.00.01, 13.00.03 / Ярослав. гос. пед. ун-т им. К.Д. Ушинского. Ярославль, 2008. 333 с.

20. Сумина В. Е. Развитие умений фасилитации общения у студентов в процессе овладения иноязычной речью: дис. ... канд. пед. наук: 13.00.08. Ростов н/Д, 2006. 189 с.

21. Тимонина Л.И. Социально-педагогическая фасилитация учебной деятельности неуспевающих школьниковподростков: дис. ... канд. пед. наук: 13.00.02: Кострома, 2002. 212 с.

22. Филозоп А.А. Фасилитация личностной адаптированности в период поздней взрослости средствами творческого самовыражения: дис. ... канд. психол. наук: 19.00.13. Воронеж, 2005. 232 с.

23. Халитов Р.Г. Особенности психосоциального диссонанса коммуникативно-волевых компонентов психики в половозрастных группах: дис. ... канд. психол. наук: 19.00.05. Казань, 2012. 173 с.

24. Халитов Р.Г., Юсупов И.М. Нелинейная модель психосоциального диссонанса // Вестник ЛГУ. 2008. № 3. С. $140-148$.

25. Халитов Р.Г., Юсупов И.М. Уровневая модель психосоциального взаимодействия субъектов // Балтийский гуманитарный журнал. 2013. № 4. С. 127-128.

26. Хисамбеев Ш.Р. Гносеологический и онтологический подход к психологическому исследованию: историкотеоретический анализ // Гуманитарный вектор. Серия: Педагогика, психология. Выпуск № 1. 2012.

27. Hermans H.J.M. The dialogical self: toward a theory of personal and cultural positioning/Culture \& Psychology. 2001. Vol. 7(3). Pp. 243-281.

Поступила в редакцию 01.08.2019

Васина Вероника Викторовна, кандидат психологических наук, доцент, профессор кафедры теоретической и инклюзивной педагогики Казанский инновационный университет им. В.Г. Тимирясова 420111, Россия, г. Казань, ул. Московская, 42 E-mail: virash1@mail.ru

\title{
V.V. Vasina \\ THE PHENOMENON OF SOCIAL INTERACTION FACILITATION: EFFECT, MECHANISMS, REGULARITIES
}

\author{
DOI: $10.35634 / 2412-9550-2019-29-3-268-275$
}

In the epoch of exponential development of civilization, social interaction becomes more and more dense and the range of representations and regulations of life is expending, and, accordingly, the probability of conflict in society increases. The research of a problem of social interaction is insufficiently provided and remains urgent in the scientific world. The author (together with R.G. Khalitov and I.M. Yusupov) developed the concept of psychosocial dissonance (notion and model) which was the base for a research of social interaction, and the probabilistic model of psychosocial dissonance became a basis for mathematical (formulas and numbers) determination and modeling of social interaction. Post- 
nonclassical science, within which the author conducts the researches, studies complex self-developing systems, natural complexes that include the human being, with the expansion of the scope of concepts of scientific methodology and scientific approach to the human being. To understand the facilitation of social interaction in the presence of an observer, the "anthropological principle" is used, which establishes a link between the existence of a person (as an observer) and the physical parameters of the world. On the basis of theoretical researches the concept is introduced and the effect of facilitation of social interaction is shown. The description of the mechanism of facilitation of social interaction on the basis of the model of psychosocial dissonance and level model of psychosocial phenomena is offered. Empirical researches are carried out and regularities of social interaction facilitation are shown and the method of definition of (numerical) influence of the facilitator on social interaction is offered. The model of social interaction facilitation can become the basis for further psychological research and provides an opportunity to apply the results for use in psychological practices, as well as in the training of competent professional facilitators.

Keywords: mechanisms and regularities of facilitation, model of social interaction, facilitation of social interaction, psychosocial dissonance, system and ontological approach.

Vasina V.V., Candidate of Psychology, Associate Professor, Professor at Department of theoretical and inclusive pedagogics

Kazan Innovative University named after V.G. Timiryasov

Moskovskaya st., 42, Kazan, Russia, 420111

E-mail: virash1@mail.ru 